\title{
DOCÊNCIA NO SISTEMA PENITENCIÁRIO: O QUE AS NARRATIVAS DE PROFESSORES REVELAM SOBRE A EDUCAÇÃO DE ADULTOS PRIVADOS DE LIBERDADE
}

\author{
TEACHING IN THE PENITENTIARY SYSTEM: WHAT TEACHER NARRATIVES REVEAL ON THE EDUCATION OF \\ PRIVATE FREEDOM ADULTS
}

DOCENCIA EN EL SISTEMA PENITENCIARIO: LO QUE LAS NARRATIVAS DE PROFESORES REVELAN SOBRE LA EDUCACIÓN DE ADULTOS PRIVADOS DE LIBERTAD

\author{
JOSÉ, Gesilane de Oliveira Maciel ${ }^{1}$ \\ TORRES, Eli Narciso da Silva²
}

\section{RESUMO}

Este artigo procura demonstrar as especificidades da oferta de Educação de Jovens e Adultos (EJA) em escolas inseridas em prisões, conforme previsto na Lei de Execução Penal (LEP), como uma das assistências necessárias para promover a integração social do apenado. O objetivo foi analisar a função docente a partir de narrativas de professores que lecionam em escolas inseridas no sistema penitenciário. Para isso, foram realizadas entrevistas com docentes de diferentes municípios do estado de Mato Grosso do Sul. Nesse contexto, a análise indicou que o(a) professor(a) procura desempenhar suas atividades pedagógicas, imerso numa constante busca de atribuir novos significados à atividade que desenvolve.

Palavras-chave: Função docente. Educação de privados de liberdade. Professor e sistema penitenciário. Escola na prisão. EJA no âmbito do sistema penitenciário.

\section{ABSTRACT}

This article seeks to demonstrate the specificities of the provision of youth and adult education (EJA) in schools inserted in prisons, as provided for in the Criminal Enforcement Law (LEP), as one of the necessary assistance to promote the social integration of the victim. The objective was to analyze the teaching function from narratives of teachers who teach in schools inserted in the penitentiary system. For this, interviews were conducted with teachers from different municipalities in the state of Mato Grosso do Sul. In this context, the analysis indicated that the teacher seeks to carry out his pedagogical activities, immersed in a constant search to assign new meaning to the role he develops.

Keywords: Teaching function. Deprivation of liberty education. Teacher and penitentiary system. School in prison. EJA within the penitentiary system.

\section{RESUMEN}

Este artículo busca demostrar las especificidades de la oferta de educación de jóvenes y adultos (EJA) en escuelas insertadas en prisiones, conforme a lo previsto en la Ley de Ejecución Penal (LEP), como una de las asistencias necesarias para promover la integración social del apenado. El objetivo fue analizar la función docente a partir de narrativas de profesores que enseñan en escuelas insertadas en el sistema penitenciario. Para ello, se realizaron entrevistas con docentes de diferentes municipios del estado de Mato Grosso do Sul. En ese contexto, el análisis indicó que el profesor, busca desempeñar sus actividades pedagógicas, inmerso en una búsqueda constante de atribuir nuevo significado al papel que desarrolla.

Palabras clave: Función docente. Educación de los privados de libertad. Profesor y sistema penitenciário. Escuela en la cárcel. EJA en el marco del sistema penitenciario.

\footnotetext{
1 Universidade Estadual Paulista - UNESP - São Paulo - Brasil.

2 Universidade Estadual de Campinas - UNICAMP - Campinas - São Paulo - Brasil.
} 


\section{INTRODUÇÃO}

Atualmente o Brasil conta com mais de 700 mil pessoas em privação de liberdade, e a média de $10 \%$ desta população encontra-se vinculada à educação formal. Enquanto $2 \%$ das pessoas presas frequentam atividades inerentes às modalidades de educação profissional, remição pela leitura ou pelo esporte (DEPEN, 2017).

O atendimento educacional em unidades prisionais, assim como as demais assistências penitenciárias (saúde, material, religiosa, social, jurídica) encontra previsão na Lei de Execução Penal (BRASIL, 1984), que tem como meta a integração social da pessoa em privação de liberdade e, também, significa uma segunda chance àqueles que não tiveram oportunidade para estudar em idade hábil. Por isso, a educação é um meio eficaz para a promoção e aquisição de novos conhecimentos, e além disso, a elevação do grau de instrução pode auxiliar na inserção social do egresso do sistema penitenciário.

A oferta da educação em prisões foi institucionalizada, gradativamente no país, por meio de ações dos poderes executivo, legislativo e judiciário, dentre as quais, encontram-se, as Diretrizes Nacionais prevista pela Resolução $N^{\circ}$ 2, de 19 de maio de 2010, que dispõe sobre a oferta de educação para jovens e adultos em privação de liberdade nos estabelecimentos penais.

A lei 12.433/2011 (alterou a LEP e garantiu o direito ao preso de reduzir um dia de pena a cada 12 horas de frequência escolar) e Decreto 7.626 /2011 que institui o Plano Estratégico de Educação no âmbito no sistema prisional, referendado pelos ministérios da Educação e da Justiça. Em 2013, o Conselho Nacional de Justiça - $(\mathrm{CNJ})$, presidido pelo Ministro Joaquim Barbosa, fomentou o direito à remição pela leitura, por meio da Recomendação $n^{\circ}$. 44/2013, expandindo o entendimento de algumas comarcas aos demais tribunais sobre "[...] atividades educacionais complementares para fins de remição da pena pelo estudo e estabeleceu critérios para a admissão pela leitura" (CNJ, 2013; TORRES, 2017, p. 239).

Por outro lado, cabe ao professor o desafio imposto pelas especificidades da EJA que é concebida, especialmente, para o atendimento educativo de jovens e adultos não escolarizados ou com baixa escolaridade. Com isso, uma das questões que permeia o debate sobre os desafios que essa modalidade de ensino impõe, sobretudo, a oferta para privados de liberdade, se constitui na função do trabalho pedagógico, posto que se trata de uma educação de caráter popular, e caracterizada pelo fortalecimento da luta pelo direito à diversidade, atribuindo assim, por consequência, um novo significado ao papel do educador. Entende-se, que a referência à educação popular se dá a partir da constituição de uma práxis social, a qual é produzida no interior de grupos populares (FREIRE, 2001), no caso em questão, considerando, inclusive a realidade e o cotidiano dos estudantes em situação de privação de liberdade.

Porém, a priorização da segurança e disciplina prisional, em detrimento de outras ações que ocorrem no interior da prisão são questões antagônicas que interferem no desempenho, por exemplo, da escola, e consequentemente nas ações e/ou omissões dos professores. Por isso, pensar a oferta da 
EJA no interior do cárcere, implica, a priori, em identificar o que caracteriza a função do professor que desenvolve atividades pedagógicas no espaço da prisão.

Assim, ao considerar o espaço prisional, imbricado no processo de ensino e aprendizado, a docência vivencia alguns obstáculos a serem ainda transpostos. Dentre eles, pode-se destacar que as condições de aprisionamento são instituídas em ambiente hostil, com valorização das medidas disciplinares, de segurança e vigilância institucional, as quais, em certa medida, sobrepõem a gradativa implementação e a efetividade da política que visa a garantia do direito à educação aos privados de liberdade.

Perseguindo essa chave de análise, o objetivo deste artigo é ampliar a compreensão sobre a função docente. Para isso, o estudo se utilizou de entrevistas e análise de narrativas ${ }^{3}$, que empregou a técnica da coleta de dados e possibilitou agregar a experiência do que é vivido e percebido pelos sujeitos participantes, ou seja, (professores/professoras) que lecionam na modalidade EJA no contexto da prisão e, ao mesmo tempo, abordar as percepções individuais e sociais vivenciadas e agora narradas pelos entrevistados. As narrativas foram recolhidas no transcurso do mês de junho de 2018, por meio de entrevistas com sete docentes que atuam em escolas localizadas no interior de unidades prisionais, no estado de Mato Grosso do Sul4.

De todo modo, as entrevistas foram realizadas em espaços externos à prisão, na intenção de buscar um ambiente favorável para que o (a) professor (a) tivesse maior tranquilidade durante o diálogo que retrataria a sua experiência docente. Houve a utilização de gravador de áudio e, posteriormente, a transcrição e análises dos dados. Nessa transcrição, foram observadas as características para-linguísticas, por exemplo, o tom de voz, as pausas, a demonstração de sentimentos, satisfação ou decepção, entre outros aspectos.

Durante a apreciação dos dados, a metodologia adotou a perspectiva da análise de discurso, com fundamentação teórica em Bakhtin (1997, 2004).

Bakhtin (1997) entende a pesquisa biográfica ou o gênero narrativo de uma vida, como uma forma do sujeito objetar seu eu e sua vida em um plano artístico com princípio organizador do vivido, e que pode dar forma à consciência, à visão, ao discurso que tem sobre sua própria vida. $\mathrm{O}$ teórico russo considerava os valores biográficos como valores comuns compartilhados pela vida e pela arte; em outras palavras, eles podem determinar os atos práticos e suas finalidades e se efetuar na rememoração do passado como uma natureza estética e na memória do futuro como uma ordem moral.

Logo, a fala, a enunciação possui natureza social e está imbricada às condições de comunicação e as estruturas sociais e, portanto, configura-se como expressão das relações humanas e das lutas sociais.

\footnotetext{
${ }^{3}$ Amparada pelo Termo de Consentimento Livre e Esclarecido e aprovado pelo Comitê de Ética em Pesquisa.

${ }^{4}$ Os dados analisados referem-se aos resultados preliminares de pesquisa de Doutorado.
} 
Baseado na perspectiva bakhtiniana, a compreensão do discurso do sujeito se estabelece por meio do dialogismo, que se configura como uma relação de sentido situada entre os diferentes enunciados na comunicação verbal, inclusive o próprio ato de compreender se estabelece como uma relação dialógica.

Para o autor, o ouvinte que recebe e compreende a significação de um discurso adota simultaneamente uma atitude responsiva ativa, em que concorda, discorda (total ou parcialmente), completa, adapta, etc. (BAKHTIN, 1997). A responsividade ativa, portanto, se estabeleceu por meio da relação dialógica do pesquisador com a narrativa dada pelo sujeito participante da pesquisa, desenvolvida por meio de uma concordância, adesão, objeção, etc.

Ao assumir esse formato, tornou-se possível analisar as narrativas não apenas como uma listagem de acontecimentos, mas também, como uma tentativa de relacioná-las no espaço, tempo, sentidos, valores, percepções, e outros aspectos que envolvem as ações concretas que ocorrem no trabalho docente, bem como seus aspectos subjetivos, que permeiam suas falas, entre o que deve ou não deve ser dito, e as operações relacionadas ao sentido que o enredo dá a narrativa.

\section{NOVAS CONFIGURAÇÕES DA FUNÇÃO DOCENTE}

Para dialogar sobre como vem se efetivando a função do docente em escolas inseridas em ambientes penitenciários, cabe observar que a escola (na prisão ou não) é uma instituição social, forjada em contexto histórico-político e social mais amplo e em constante transformação econômica, principalmente 5 .

O processo de empobrecimento significativo da sociedade brasileira, e a segregação de parcela significativa no sistema prisional elencam pistas importantes sobre práticas, ou melhor, instituições que cumprem o papel de segregar sujeitos marginalizados socialmente da sociedade de consumo em ambientes estatais. Porém, qual o perfil da escolarização dos custodiados brasileiros?

Dados do Departamento Penitenciário Nacional (2017) indicam que 17\% dos presos estão em fase de alfabetização, $56 \%$ estão matriculados no ensino fundamental, $26 \%$ estudam no ensino médio e $1 \%$ está vinculado a cursos de ensino superior (DEPEN, 2017).

Sendo assim, são sujeitos com baixa escolaridade e, como vimos, com acesso restrito à escola na prisão. São pessoas em processo de escolarização, que apesar da condição de presos, mantêm as demais garantias constitucionais, inclusive a garantia universal de direito à educação. Essa luta é abarcada pelas políticas para a pessoa privada de liberdade e impacta diretamente na criação de projeto político pedagógico próprio e, também, na atividade docente.

\footnotetext{
5 Partindo desses pressupostos e, sobretudo, considerando que as relações sociais são calcadas numa sociedade estratificada em classes sociais e sistema capitalista, cabe observar as alterações educacionais, dentre elas, a expansão e interferências do ensino elementar, como um possível mecanismo de controle das massas e a favor dos interesses do capital econômico (DI GIORGI; LEITE, 1995).
} 
Numa digressão até ao o início da década de 1960, tudo leva a crer que a educação popular acontecia com experiências limitadas e restritas a algumas regiões do país. Entretanto a partir desse período (1961-1964), Paulo Freire implementa movimentos de educação popular e, posteriormente, em 1964, a prática conhecida como método Paulo freire assume a alfabetização de adultos expandida a classe de trabalhadores, por meio da realização de experiências no campo e na cidade. Nesse processo, adota-se um novo modelo de educação marcado pelo teor ideológico e genuinamente político. Movimento extinto meses após a institucionalização em decorrência do Golpe de 1964. Nesse ínterim, com o advento do período de abertura política, ocorreu intensa associação entre educação popular e os movimentos sociais contemporâneos.

A partir da década de 1980, as discussões sobre o problema educacional começaram a ganhar espaço nas agendas políticas, relacionando a precariedade do ensino e as mazelas da educação à emergência da erradicação do analfabetismo, compreensão que gerou distintos movimentos pela efetividade da educação popular.

Pode-se dizer, que no decorrer das décadas a EJA foi ampliada, por intermédio de políticas educacionais específicas para a sua oferta, as quais consideram o professor e a função professoral, como aquele indivíduo que desenvolve atividades pedagógicas perseguindo, em tese, o compromisso político que se consolida em uma perspectiva ética e comprometida com as questões sociais, visando, em especial, a formação crítica e criativa dos estudantes.

A expansão da oferta de ensino às classes populares provoca a transição do ensino direcionado à elite, para um ensino de massas, e consequentemente, implica em uma nova reconfiguração do papel docente, com vista a premissa de se construir um cenário educativo favorável à inclusão.

Diante da ampliação da oferta educacional, Fanfani (2007) ressalta que os professores encontram dificuldades em adaptar sua forma de ensinar ao público das massas populares que, por vezes, comparecem às escolas com problemas de disciplina, motivação e com um déficit de interesse educacional. Os docentes precisam encontrar novas formas de agregar conhecimento ao aluno e, ao mesmo tempo, manter sua adesão ao "ideal” de igualdade de oportunidades.

Também é patente o conflito relacional gerado a partir do exercício da docência, entre eles, acentua-se a expectativa social que o(a) professor(a) seja amigo(a) do aluno, apoiador e facilitador em seu desenvolvimento. Expectativa incompatível com a função seletiva e avaliadora do profissional. Por outro lado, a reforma dos conteúdos curriculares gerou incertezas quanto ao desenvolvimento das atividades do professor (ESTEVE, 1995, 1999). Essas condições, portanto, acarretam como resultado, a menor valorização social do professor e instabilidade quanto a sua tarefa pedagógica.

Ao analisar esses indicadores, fica evidente as inúmeras mudanças sociais e históricas que implicam compreender a função docente. Tais fatores geram problemas como, o aumento da crise da profissão, problemas na delimitação dos campos de competência, crise de identidade refletida em uma situação de mal-estar, conflitos gerados em torno de sua imagem social, além das inseguranças 
provocadas pelas contradições que perpassam a natureza e as características de sua função educacional, marcadas por um percurso repleto de lutas e conflitos.

Nesse sentido, faz-se necessário participar ativa e criticamente das novas demandas sociais, ampliar seu conhecimento científico e tecnológico, e assumir uma preocupação educacional que perpassa por um comportamento democrático, igualitário, que respeite as diversidades, as especificidades de cada comunidade e a realidade social em que a escola está inserida.

O docente tem como ofício principal, o processo de ensinar, entretanto enfrenta o desafio de aproximar a perspectiva teórica à prática das atividades pedagógicas, de forma que a educação faça sentido no processo de escolarização do indivíduo livre ou privado de liberdade. Além disso, é fundamental que esse docente esteja atento às demandas sociais oriundas do contexto do aprisionamento, assumindo uma preocupação com relação à formação para a cidadania (integração social como prevê a LEP) e para o respeito às diversidades, não as perdendo de vista. Apesar de sua imersão em ambiente disciplinador, o educador, munido de consciência política, pode contribuir efetivamente para o processo de formação de homens e mulheres em situação de privação de liberdade.

Nessa dinâmica, a interlocução entre docentes e discentes pode ocorrer numa perspectiva transformadora, mesmo em espaço de reclusão. Por isso, as distintas perspectivas narradas pelo professor (a) sobre como concebe a sua função no espaço penitenciário foram analisadas e serão detalhados na seção seguinte.

\section{NARRATIVAS E DOCÊNCIA NO CÁRCERE}

O ingresso em unidades penitenciárias de Mato Grosso do Sul é controlado por operadores do sistema penitenciário. Ao adentrar ao espaço prisional, o docente precisa se identificar na portaria do estabelecimento, por meio de documento oficial, em regra, carteira de Registro Geral (RG). É obrigatório o uso de jaleco adotado pela escola, na cor verde água. A determinação da Agência de Administração do Sistema Penitenciário (Agepen) é para que ocorra a revista dos materiais didáticos, posterior liberação, e ingresso à unidade. O procedimento é substituído, em caso de revista mecânica, por meio de scanners corporais e/ou detectores.

Cabe considerar que cada unidade tem especificidades próprias e estrutura física distinta, entretanto, em alguns presídios, até chegar na sala de aula, o docente passa por vários portões e grades. Inclusive em algumas unidades, o educador transita entre os internos identificados como "celas livres ou trabalhadores", os quais caminham com certa liberdade entre os corredores das prisões.

Para iniciar as aulas, os agentes penitenciários se responsabilizam pela soltura dos alunos de suas celas, solários e pavilhões, em direção à escola. Durante o deslocamento pelos corredores, os estudantes devem andar em fila, de cabeça baixa e com as mãos para trás. Ao se aproximarem da escola é perceptível a elevação dos ombros, da cabeça, enquanto os olhos dos sujeitos buscam a 
escola e a coluna vertebral toma posição ereta, anunciando a entrada num espaço de maior liberdade do corpo. Características incorporadas em espaços disciplinadores e de assujeitamento dos corpos, como observou FOUCAULT (2010), ao analisar a história das prisões.

As salas de aulas são organizadas em espaços compostos por carteiras escolares, armário de aço, lousa e giz. Nas prisões estaduais, o professor fica próximo aos seus alunos sem separá-los por grades, como em um espaço escolar fora da prisão. As escolas e/ou a estrutura das salas de aulas não são padronizadas, especialmente porque na maioria dos casos, as salas foram adaptadas para a oferta educacional. Ao mesmo tempo existem alguns espaços bem reduzidos e com pouca ventilação.

No geral, os alunos são respeitosos e educados. Cabe pontuar, também, que é visível a situação degradante dos aprisionados, ocasionada pelo superencarceramento, além das condições econômicas, sociais e de baixa escolaridade dos alunos. É perceptível que alguns estudantes se dedicam às aulas e aproveitam, em especial, os momentos de aprendizagem e o convívio social proporcionado fora da cela. Enquanto outros se utilizam do horário das aulas para negociações de objetos ilícitos ou lícitos, considerando que a escola possibilita o convívio entre os presos de diferentes pavilhões, solários ou alas. Como Torres (2011, p. 117) descreve: "Nessas oportunidades, sem distinção de crime ou pavilhão, eles se unem em busca de um objetivo maior - negociar pertences (objetos de uso pessoal), entorpecentes ou, até mesmo, celulares". Via de regra, todos permanecem atentos ao que acontece naquele ambiente e observam a todo tempo a movimentação dos agentes penitenciários.

Nas unidades estaduais, as aulas acontecem, resguardadas as exceções, durante o dia em dias letivos. A rotina escolar aparentemente se confunde com a dinâmica de escolas regulares, fora da prisão, porém, a realidade é bastante distinta de outros espaços escolares. Não é raro, por exemplo, as interrupções de aulas por inúmeros motivos: às vezes porque o aluno foi redirecionado ao atendimento médico, jurídico com o advogado ou porque ocorreu revista "geral" nas celas. A imprevisibilidade na rotina ressoa, em certa medida, no comportamento apreensivo e, algumas vezes, agitado dos alunos.

Uma parcela significativa de custodiados da justiça faz uso abusivo de substâncias psicoativas ilegais, e não há tratamento ou acompanhamento eficaz, e tão pouco o controle sobre o ingresso de drogas nas unidades prisionais brasileiras. Por isso, alguns alunos, motivados pela dependência e também pelo fácil acesso as drogas, se deslocam à escola munidos de substâncias psicoativas, as quais são utilizadas durante as saídas para o banheiro, mesmo sobre a vigilância de agentes penitenciários.

Essas, dentre outras situações, são rotineiras no ambiente escolar prisional, mas é também, nesse cenário, que o professor desenvolve suas atividades pedagógicas. Assim, a partir dessas especificidades, buscamos, por meio das narrativas dos docentes, identificar como eles compreendem a função docente e o aprisionamento aliados às complexidades do sistema penitenciário.

Inicialmente, os professores relatam que para lecionar no contexto prisional, é preciso que o educador tenha um "perfil" específico, 
Não é todo professor que tem perfil para trabalhar lá dentro. A gente tem que ter um perfil desde a vestimenta, dos acessórios que nós utilizamos, principalmente a mulher, e em como você se portar em sala de aula. Não ficar muito de costas, não abaixar muito, não usar um perfume muito forte, maquiagem que vai chamar a atenção do aluno, até a questão de você conversar com eles, o que você vai conversar, o que você fala e o que você ouve... Nem tudo que você pode falar para ele e nem tudo que ele pode falar para você também. É lógico que aluno é aluno em qualquer lugar. Então ele sempre vai querer conversar sobre as situações da vida dele, particular. E aí cabe a você, dar abertura do que ele pode e o que ele não pode. (P1).

É bem difícil encontrar um professor que tenha o perfil. Ele pode começar a trabalhar no ensino prisional, mas para ele ficar, ele tem que ter uma postura ética muito grande. Ele tem que ser uma pessoa muito íntegra, porque senão não vai ficar. [...]. Existe uma coisa que você pode ter contato com o aluno, porém você tem que ser o mais ético, mais neutro possível. Porque o aluno quer saber da sua vida, ele quer saber onde você mora, o que você faz, quantos filhos você tem. [...]. Você tem que evitar esse tipo de conversa, ser o mais ético possível. (P2).

Os relatos demonstram, inicialmente, que o perfil docente se refere a uma postura ética, de discrição quanto a sua vida pessoal, na vestimenta e na postura. Faz-se necessário um cuidado singular ao evitar o uso de perfume muito forte, maquiagem, acessórios ou "algo" que possa desviar a atenção, tanto dos alunos quanto das alunas. A neutralidade aparece nas falas, sob a égide do cuidado e vigilância para reduzir a possibilidade de envolvimento emocional. Linha tênue, visto que a escola é antes de tudo, espaço de sociabilidade e, por outro lado, o confinamento leva o indivíduo a profunda tristeza, depressão, carência afetiva e questionamento sobre sua própria existência, especialmente devido à perda de conexão com a família, e até mesmo, por sua identidade que se desagrega do mundo social.

Evidente que a postura ética não está imbricada apenas a espaços penitenciários, entretanto, no ambiente de aprisionamento, a postura e a palavra adquirem maior peso nas relações estabelecidas entre os privados de liberdade, considerando que coexistem outras regras sociais e de convivência. Nesse cenário, há relatos de estudante que observa atentamente a postura do professor, e quando possível, tenta aliciar o docente, testando-o com pedidos ilícitos, tanto para se beneficiar a partir de sua posição de agente externo à penitenciária, como para verificar se pode extrapolar os limites éticos estabelecidos entre professor e aluno. 
O princípio ético, na visão de Freire (1998), diz respeito à natureza do ser humano, pois o ensino dos conteúdos não pode ser alheio à formação moral do educando, logo, educar significa formar, dar testemunho, vivenciar a experiência da docência de mãos dadas com a decência e a seriedade.

\begin{abstract}
Não podemos nos assumir como sujeitos da procura, da decisão, da ruptura, da opção, como sujeitos históricos, transformadores, a não ser assumindo-nos como sujeitos éticos. Nesse sentido, a transgressão dos princípios éticos é uma possibilidade, mas não é uma virtude. [...] Não é possível ao sujeito ético viver sem estar permanentemente exposto à transgressão da ética. (FREIRE, 1998, p. 19).
\end{abstract}

Para o autor, a ética é indispensável à convivência humana, por isso, no contexto educacional, faz parte de uma posição política e pedagógica em que o indivíduo tem a opção de escolher, de decidir, comparar, valorar, intervir e avaliar o que a transgressão pode trazer como consequências na constituição do sujeito aluno. Sob o mesmo aspecto, Rios (2001) considera a ética como um caráter reflexivo e não normativo, que se configura como uma escolha, quando o indivíduo avalia não apenas segundo os valores que lhe são colocados, mas leva em consideração a perspectiva de realização do bem comum. Nesse caso, a perspectiva ética se constrói na vida coletiva e na formação da cidadania. "É tarefa dos professores contribuir com seu trabalho para essa formação. Eles o farão, se sua ação se realizar continuamente na direção da competência, na articulação dialética das dimensões dessa competência" (RIOS, 2001, p. 107).

Freire (2001) ainda amplia a concepção ética, ao considerar que sua dimensão não se restringe à competência do educador, à sua formação ou ao cumprimento de seus deveres, que se estenderia à pessoa humana dos educandos. Sua percepção é de uma ética fundada em uma postura substantivamente democrática porque, não sendo neutra, a prática educativa, exige do educador uma vigilância permanente no sentido da coerência entre o discurso e a prática.

Contudo, adotar esse perfil polido e ético, não diz respeito ao relacionamento estabelecido apenas com os alunos, mas a todos os envolvidos com o sistema carcerário, que observam atentamente o trabalho desenvolvido pelo professor,

Então essa questão da sua conduta, é o tempo todo policiada porque os agentes estão ali. Por isso que eu falo, em vários momentos, o que mantém o professor dentro da unidade prisional é esse perfil dele, é esse equilíbrio (P7).

Para os(as) professores(as) entrevistados(as), o perfil docente desejável, é formado por comportamentos centrais, assim, o educador deve entrar na unidade prisional despido de preconceitos e com equilíbrio emocional mesmo diante da rotina repressora e do controle disciplinar imposto pelo ambiente. Logo, torna-se fundamental acrescentar outras especificidades a essa profissão, entre elas: 
que seja um profissional preparado para criar situações pedagógicas que extrapole os muros da prisão, que leve o educando a se reconhecer como participante da sociedade e possa, por meio das disciplinas curriculares, perpassar pelos temas voltados aos direitos humanos, cidadania, ética e valores sociais.

Outro aspecto apontado pelos docentes, refere-se à necessidade em desempenhar uma função criativa, especialmente, em decorrência da pressão disciplinar inerente ao ambiente carcerário,

Porque nem tudo pode entrar no sistema prisional, e tudo tem que passar primeiro pela disciplina porque nós sabemos que lá têm as restrições. Então isso é muito desafiante porque a gente acaba tendo que criar. [...]. Então, o trabalho no sistema ele requer muita criatividade. (P1).

Eu sempre levei todos eles com essa questão do diálogo, da dinâmica da aula e da reflexão. Isso é imprescindível para os alunos da EJA. Sem essa questão você não consegue prender o aluno, atrair o aluno para ele aprender, ele ter gosto pela escola. (P1).

O professor no ensino prisional tem que estar sempre buscando novos conhecimentos porque é desafiador, é uma clientela diferenciada. (P2).

As limitações impostas pelas condições de segurança, vigilância e disciplina figuram entre os principais entraves para desenvolver ações criativas. A segurança no sentido (lato sensu) não permite muita movimentação de alunos e professores, e acaba impedindo maior dinâmica no processo de ensino e aprendizagem, entretanto, na perspectiva dos docentes, é fundamental que suas ações pedagógicas estejam imbricadas ao processo de criar e reconstruir novas práticas, que sejam dinâmicas, criativas e despertem no aluno interesse pelo processo de aprender.

Como a grande maioria desses estudantes não estudou em idade própria, é fato que estavam anteriormente desvinculados ao processo de escolarização formal, com pouca habilidade para leitura, escrita, expressão oral, cálculo, solução de problemas, além dos conhecimentos mais amplos, como as habilidades, valores e atitudes. Logo, tal situação gera como consequência, uma nova demanda a função do professor, que necessita de criatividade na tentativa de atrair o aluno a adquirir o gosto pela escola.

Além disso, há o problema da alta taxa de evasão e rotatividade de estudantes, o que prejudica a permanência e continuidade desses na escola. Por outro lado, caso o aluno não consiga compreender a educação como um valor para a vida, a opção recai sobre a desistência dos estudos, e 
por consequência, busca se integrar a outras atividades vistas como mais vantajosas, como é o caso do trabalho prisional.

Tem muito problema de evasão. [...]. Eles têm muitos problemas, então qualquer probleminha é suficiente para eles faltarem, não ir a aula, desistir da escola, qualquer problema que ele está passando ele acaba desistindo, e por vezes eles trocam o setor de trabalho, eles começam a trabalhar e param de ir na escola. Preferem trabalhar do que estudar. [...]. E, às vezes, outro sai de alvará e aí ficando aquela lista enorme com poucos alunos.

É atribuída grande responsabilidade ao docente em minimizar o problema da evasão, e contornar a frequente desistência dos alunos. Entretanto, a tarefa é complexa, considerando que o aluno privado de liberdade não possui as disposições necessárias para se engajar nos aspectos afetivo e cognitivo do mundo escolar.

Para Souza (2018), a própria condição social do estudante impede que seja construída uma relação afetiva positiva com o conhecimento. Sendo assim, é comum que o aluno sinta que a escola não está adequada à sua realidade e visão de futuro, o que gera a sensação de perda de tempo. Nesse caso, torna-se ainda mais desafiadora a responsabilidade do docente em possibilitar, durante a ação de ensino e aprendizagem, a problematização de questões inerentes ao fracasso escolar como consequência de um processo histórico, que se reproduz em grande medida como realidade das classes populares, e assim, relativizar com o estudante preso, a inculcação neoliberal das responsabilizações apenas individuais.

Haddad (2002) amplia a explicação sociológica a respeito dos altos índices de desistência na EJA, sobretudo, quando destaca entre outras questões, que a escola reproduz a estrutura de desigualdade social presente na sociedade capitalista, configurando-se como distante da realidade e das necessidades concretas dos alunos. Da parte dos estudantes, muitos se consideram incapazes e fracos, introjetando a concepção da ideologia dominante do fracasso entre alunos na mesma condição.

O problema é reconhecidamente elevado em programas de educação de jovens e adultos, em função não apenas de fatores internos aos processos de ensino e aprendizagem, provocados pelas dificuldades inerentes a essa modalidade de educação, como também devido a fatores externos vinculados às difíceis condições de vida dos alunos (Haddad, 2007).

Ireland (2012) complementa ao problematizar que a EJA, ao buscar contribuir para a superação de desigualdades, às vezes, reforça (ou reifica) o estigma que trataria da oferta educacional, com qualidade duvidosa, gestada intencionalmente para as pessoas das camadas mais pobres da população. Quando o autor cita a "oferta duvidosa", diz respeito à formação do educador de adultos, os conteúdos, o tipo de oferta e os materiais didáticos, considerados em sua ótica, como inconsistentes. 
Outra questão abordada na narrativa dos professores, diz respeito ao fato de lidarem, constantemente, com situações adversas à função, como a movimentação e/ou negociações dos alunos em sala de aula, bem como aprender a lidar com situações complexas, a exemplo dos estudantes acometidos de dependência de substâncias psicoativas,

A gente sabe que o aluno vai para a sala de aula e, às vezes, não vai para estudar, mas a gente sabe que ele vai para encontrar fulano que mora em tal lugar e que ele quer falar. Então, assim, nós sabemos que tem muito disso, então o professor tem que ter olhos por todos os lados para observar tudo. $[\ldots](P 1)$.

Aquele aluno que vem com muito sono para a sala, às vezes, ele é dependente, ele tem alguma situação. A gente sabe que dependendo do local onde ele dorme, se for superlotado ele não dorme bem, e vem para a sala com sono. Aquele que toma algum medicamento forte e tem algum problema. (P1).

E a situação também muito comum é o aluno, ele descer para estudar sob efeito de droga, principalmente maconha. Então assim, isso atrapalha no rendimento, acaba dificultando um pouquinho. (P3).

Os(as) entrevistados(as) narram a expectativa que o educador seja apto para resolver conflitos alheios ao processo de ensinar, e em condições de se adaptar e problematizar diferentes situações de acordo com as urgências da realidade desses sujeitos. Além do mais, que também seja um profissional relacional, que exerça a escuta e esteja sensível às necessidades do estudante, buscando, inclusive, a construção de novos sentidos a partir da realidade de cada educando.

Ao encarar tais pilares profissionais, fica evidente que a profissão assume o desafio de tornar a vida mais satisfatória para o estudante privado de liberdade, ao fazê-lo perceber que sua aprendizagem está, para além da arquitetura rígida, fria e contraditória imposta pela prisão, imbricada a uma formação mais sólida e crítica, com possibilidades de vislumbrar diferentes oportunidades de vida, quando em condição de liberdade.

No trabalho docente não se pode desconsiderar a formação integral do ser humano e reduzir a tarefa pedagógica a um puro treino técnico do conteúdo, em desrespeito à condição que o aluno se encontra em sala de aula. Diante disso, segundo Freire (1998), ensinar exige saber escutar, o que vai além da possibilidade auditiva do indivíduo. "Escutar, no sentido aqui discutido, significa a disponibilidade permanente por parte do sujeito que escuta para a abertura à fala do outro, ao gesto do 
outro, às diferenças do outro" (FREIRE, 1998, p. 135). Logo, a atitude de escuta faz parte do papel do professor, como um ato democrático, solidário e humano.

$\mathrm{Na}$ visão de Onofre $(2007,2011)$, cabe ao educador, pelo diálogo com o educando, compreender sua história, apreender sua realidade social passada e atual em uma aproximação críticoreflexiva, que leve o educando a se perceber como um sujeito protagonista de sua própria história, que Ihe permita dotar-se de ferramentas que Ihe garantam uma reinserção social, de forma a resgatar ou aprender outra forma de se relacionar com o outro, além de contribuir com a desconstrução da identidade do homem criminoso.

Imbernón (2016) atribui ao professor componentes geradores de especificidades da profissão docente, referindo-se a uma atividade de trabalho permanente, como um educador trabalhador do conhecimento que exerce atividade pública, emite juízo e toma decisões em circunstâncias sociais, políticas e econômicas, isto é, um profissional que se enquadra em uma conjuntura que o condiciona e que requer uma formação específica em diversas capacidades. Sob esse ponto de vista, o docente é um profissional do conhecimento mais que um profissional do ensino, que necessita conquistar espaços que possibilitem a ampliação dos debates democráticos e precisa dominar uma série de capacidades e habilidades especializadas.

Diante desses componentes geradores de especificidades da profissão docente, observa-se que existem conhecimentos que distinguem os professores que atuam em unidades prisionais com relação a outros profissionais, que perpassam pela necessidade do docente adquirir um sólido saber científico com relação à realidade do sistema prisional, que domine os conhecimentos técnicodidáticos, assuma os saberes experienciais como a ampliação de novos sentidos às suas práticas, que a reflexão e o questionamento intelectual de suas ações pedagógicas façam parte de sua rotina, e comunique essas experiências gerando novas aprendizagens docentes, de forma que sejam integradas à sua profissão.

Outro tópico que merece atenção nos relatos dos docentes, refere-se à necessidade do professor trabalhar a autoestima do aluno.

E cabe a gente, que é professor trabalhar primeiro na questão da autoestima. [...]. Esse é o papel de um professor dentro do presídio, transformar. Não é só ensinar a ler e escrever, isso qualquer pessoa faz [...]. Mas [ensinar] a questão da cidadania, a questão da autoestima, da questão de transformar a vida daquelas pessoas ali é superimportante. (P1, grifo nosso).

A gente tem que estar chamando o aluno, conversando com ele, além de ser professor tem que ser psicólogo também. Teve uma vez que um aluno meu queria suicidar, devido aos problemas que ele estava passando. Aí eu o chamei na sala, conversei com ele bastante, expliquei muita coisa para ele, 0 
que ele poderia perder. A vida é tão boa, por que suicidar? Expliquei muita coisa para ele. Ele resolveu voltar para a sala. Geralmente um diálogo que a gente tem com o aluno, a gente consegue resgatá-lo de volta para a sala de aula. (P4).

O trabalho do professor dentro do sistema prisional é algo assim desafiador. Porque quando eles chegam naquele lugar hostil, muitas vezes eles perdem a identidade, eles não têm autoestima, não tem valor. [...]. Mas assim, eu como professora, eu tenho essa meta de transformar o pensamento deles, de mudar. Como eles têm baixa estima, às vezes eles não acreditam que são capazes. (P6).

Diante dos enunciados, há o esforço de uma atitude de escuta, na tentativa de direcionar os alunos a uma conduta mais otimista diante das situações de conflitos e tensões que vivenciam diariamente. Tais questões geram, como resultado, múltiplas funções agregadas ao seu papel docente. Oliveira (2004) destaca que o professor se vê em meio ao seu trabalho, permeado por uma série de contradições, e a ele, são cobradas variadas funções, entre elas, como agente público, assistente social, enfermeiro, psicólogo, entre outras, e a escola pública assume e tem que responder a essas exigências que estão para além de sua formação.

Canário (1998) sintetiza algumas atribuições mencionadas pelos docentes em quatro dimensões essenciais, quais sejam: a primeira como um solucionador de problemas em contextos marcados pela complexidade e pela incerteza, e que inclusive, questione os processos de formação concebidos como processos cumulativos; a segunda dimensão é do professor que se torna um inventor de práticas, reconfigurando-se de acordo com as especificidades de cada situação e do público em questão; a terceira é do professor como um profissional da relação, que exerce uma atividade marcada pela relação face a face com o destinatário, assume uma postura de escuta e estabeleça formas de meta comunicação com os alunos sobre os processos de aprendizagem; e a quarta dimensão é do professor como um construtor de sentido, em que procura atribuir significado a uma realidade complexa e fundada a partir da história cognitiva, afetiva e social de cada sujeito.

O autor elenca dimensões pedagógicas variadas, e que necessitam de uma formação ampla e adequada para que o profissional se aproxime de um ensino direcionado às necessidades e especificidades do ambiente carcerário.

Por fim, interessante notar que mesmo diante de inúmeras atribuições, alguns docentes oferecem narrativas que atribuem a eles a função de modificar a vida e o comportamento do aluno, 
E também o professor, eu acho que tem que saber um pouco disso, de saber que você tem um papel muito importante de modificar a vida de uma pessoa assim, profissionalmente, intelectualmente, tem esse papel. (P6).

E teve casos de muitos alunos que mudaram o comportamento com a escola, essa é a nossa função. ( $P$ 7).

Nos relatos, observa-se de que há uma percepção da função docente imbricada a uma educação discursivamente redentora. Uma visão romantizada -, verdade! Mas poderia existir um outro discurso mais recorrente? Nada mais comum, já que se trata de professores que trabalham em unidades prisionais cujos alunos e alunas querem, principalmente, sua liberdade de volta.

Por outro lado, fortalecem em seus relatos o modelo implementado, ainda incipiente para a escolarização para prisões. A perspectiva de que o papel do professor passa por uma educação libertadora, não se refere apenas à liberdade física, mas se explicita muito bem ao papel da educação como processo que proporciona ao indivíduo mais do que conhecimentos científicos ou treinamento em relação a determinadas habilidades específicas. A libertação de que se fala refere-se aos "seres humanos", e, nesse nível, pode ser entendida como um papel mais amplo, de formação total dos seres humanos - assim, é possível verificar como tudo está imbricado em favor de uma narrativa, na qual o professor assume o papel de redentor.

A atuação do educador como "agente transformador", para além da docência, também é retificada pelo aluno privado de liberdade, Fernando, em depoimento ao Documentário Remição,

\footnotetext{
Dificilmente quem sai do sistema pode garantir que não vai voltar... É muito difícil. Porque o sistema não ressocializa ninguém, não. Isso aí é fantasia! O indivíduo, ele se ressocializa, ele melhora por conta própria ou com o contato de pessoas de fora, pessoas externas ao sistema. No caso, os professores, eles fazem essa função muito bem. (TORRES, 2013).
}

Na mesma direção, Santos (2007) ainda complementa que, embora a escola esteja localizada em um ambiente violento e repressor, espera-se que a prática educativa valorize a autonomia do interno, problematize sua existência e promova a dignidade dos que ali comparecem, configurando-se como propostas diferentes da rotina que o cárcere impõe.

O professor, nessa condição, configura-se como um sujeito primordial no resgate da condição de cidadania do indivíduo, a partir do auxílio no estabelecimento de vínculos que o detento perdeu ao ser afastado da sociedade. Nesse sentido, a escola torna-se um lugar de trocas, de vivências interativas, de respeito mútuo, de cooperação, de diálogo, e que pode minimizar as marcas deixadas pela pena privativa de liberdade. 
Para que ocorra tal modificação na vida do estudante privado de liberdade, é preciso, evidentemente, que o professor amplie seu repertório de ensino, incluindo preocupações sociais e de formação para a cidadania, o que requer um engajamento efetivo dos docentes nesse debate político e social.

Para responder a isto, Giroux (1997) aponta algumas possibilidades quando defende que é preciso repensar e reestruturar essa função encarando os professores como intelectuais transformadores. Na perspectiva do educador, dentro desse discurso, os professores deixam de ser vistos como meros operadores profissionalmente preparados para efetivamente, atingir quaisquer metas a eles apresentadas, e passam a ser vistos como professores livres, com uma dedicação especial aos valores do intelecto e ao fomento da capacidade crítica dos educandos.

Como ponto de partida, é preciso encarar as escolas como locais econômicos, culturais e sociais que estão atrelados às questões de poder e controle,

\begin{abstract}
Isto significa que as escolas fazem mais do que repassar de maneira objetiva um conjunto comum de valores e conhecimento. Pelo contrário, as escolas são lugares que representam formas de conhecimento, práticas de linguagem, relações e valores sociais que são seleções e exclusões particulares da cultura mais ampla. Como tal, as escolas servem para introduzir e legitimar formas particulares de vida social. Mais do que instituições objetivas separadas da dinâmica da política e poder, as escolas são, de fato, esferas controversas que incorporam e expressam uma disputa acerca de que formas de autoridade, tipos de conhecimento, formas de regulação moral e versões do passado e futuro devem ser legitimadas e transmitidas aos estudantes. [...]. Em resumo, as escolas não são locais neutros e os professores não podem tampouco assumir a postura de serem neutros. (GIROUX, 1997, p. 162).
\end{abstract}

Em vista disso, o professor deixa de ser um técnico burocrata que apenas transmite o conhecimento ou simplesmente assume um papel de treinamento de habilidades práticas, e passa a assumir uma função social, engajada em interesses políticos e ideológicos que estruturam as relações em sala de aula, e tornam o pedagógico mais político e o político mais pedagógico, o que gera a atribuição de novos valores e legitima seu ofício de ensinar, sobretudo, quando direcionado às classes populares.

\begin{abstract}
Se acreditarmos que o papel do ensino não pode ser reduzido ao simples treinamento de habilidades práticas, mas que, em vez disso envolve a educação de uma classe de intelectuais vital para o desenvolvimento de uma sociedade livre, então a categoria de intelectual torna-se uma maneira de unir a finalidade da educação de professores, escolarização pública e treinamento profissional aos próprios princípios necessários para o desenvolvimento de uma ordem e sociedade democráticas. (GIROUX, 1997, p. 162).
\end{abstract}

Sendo assim, é necessário encarar as escolas como esferas públicas democráticas, e os professores por sua vez, assumirem novos modos de enxergar o tempo, espaço e atividade docente, combinando reflexão e ação e comprometidos com o desenvolvimento de uma proposta educacional intelectual transformadora. 
Ao agregar tal perspectiva para essa discussão, assume-se uma função docente que procura ensinar, não de forma técnica e mecânica cotidianamente, mas com um ofício agregado a preocupações de natureza emancipadora, com a exploração de um conhecimento problematizado e fundado em um diálogo crítico, de forma que os alunos reclusos em prisões assumam uma voz ativa, linguagem crítica e aprendizagens que busquem a superação das injustiças econômicas, políticas e sociais, especialmente quando estiverem em condição de liberdade.

Sendo assim, essa função assume posturas de mudança e para a mudança, e se estabelece como uma referência de habilidades desejáveis, voltadas para os princípios de ética, da consciência crítica e na proposição de valores, quando coincidem com outros agentes sociais.

Em suma, fica evidente que as principais concepções a respeito da função e profissionalização docente - na condição da educação em prisões - abarcam saberes além dos conhecimentos específicos de instrumentalidade técnica racional e pedagógica. Seu ofício caracteriza-se em assumir uma postura e compromisso político de forma contextualizada e construtora de sentidos ao educando.

Faz-se necessário, da mesma forma, assumir uma função vocacional, não no sentido religioso como defendido no século XVII, mas de caráter humananista, relacional e permeado pela criatividade, como um artesão, construtor de práticas e experiências significativas. E finalmente, atuar como um profissional crítico, intelectual e questionador, que desempenhe seu ofício em busca de uma sociedade democrática, emancipadora e solidária, demonstrando preocupação permanente com a população oriunda das classes populares.

Em que pese tais funções profissionais, não se pode deixar de questionar a formação inicial e continuada para que professor desenvolva tais ações, especialmente no contexto da EJA, que ocupa um lugar de pouco prestígio entre as diferentes modalidades de ensino.

Ainda na dimensão da institucionalidade, destacam-se as condições precárias do atendimento que ainda predominam na EJA: espaços inadequados, educadoras e educadores mal pagos e com limitada formação e identidade com a modalidade, a descontinuidade, a falta de oportunidades concretas para os educandos e educandas continuarem os estudos (RIBEIRO, CATELLI JR., HADDAD, 2015, p. 42).

\section{NOTAS FINAIS}

Os relatos demonstram que o perfil docente desejável ou idealizado pelo grupo é descrito como aquele do sujeito com postura ética, discreta, desvinculado de preconceitos e com equilíbrio emocional, especialmente pelo desafio de lidar diariamente com a rotina imprevisível do local de trabalho. Somase a isso, os aspectos relacionados ao ambiente marcado pela pressão disciplinar imposta pelas regras de segurança.

Na mesma medida, faz-se necessário que o professor desempenhe ações criativas, mediando a história de vida dos sujeitos ao processo de ensinar, produzindo conhecimento a partir da escuta ativa e aproximação crítico-reflexiva com o estudante. Além disso, a busca em construir novos 
sentidos é inerente à função e ao processo de ensino e aprendizado, contribuindo, dessa forma, para relativizar a inculcação reificada sobre fracasso escolar e responsabilização individual dos sujeitos em sociedades neoliberais.

Entretanto, cabe pontuar, que o docente encontra dificuldade no processo de ensino, em geral, por falta de investimento e qualificação profissional. É comum, os educadores em exercício não possuírem nenhuma qualificação específica para atuarem com alunos em contexto de aprisionamento e assim, despreparados a priori, para desenvolverem as atividades pedagógicas na EJA no âmbito da execução penal.

Deste modo, ao elencar inúmeras atribuições a função do professor que atua no interior das prisões, faz-se necessário desenvolver um processo formativo que prepare o docente a atuar de forma interdisciplinar, mediadora, coletiva, além de outros elementos que até o momento não pertenciam à profissão. Tal tarefa é árdua, especialmente ao considerar o ambiente do cárcere.

\section{REFERÊNCIAS}

1. BAKHTIN, Mikhail. Estética da criação verbal. São Paulo: Martins Fontes, 1997.

2. BAKHTIN, Mikhail (Volochinov). Marxismo e filosofia da linguagem. São Paulo: Hucitec, 2004.

3. BRASIL. Lei de Execução Penal. Decreto-Lei n 7.210, de 11 de julho de 1984.

4. Lei $n^{\circ}$. 12.433, de 29 de junho de 2011. Altera a Lei $n^{\circ} .7210 / 84$ de 11 de julho de 1984 . Dispõe sobre a remição da pena por estudo. Diário Oficial da República Federativa do Brasil, poder Executivo, Brasília, DF, 30 de junho de 2011.

Plano Estratégico de Educação no âmbito no sistema prisional. Disponível em HTTP://www.planalto.gov.br/ccivil_03/_Ato2011-2014/2011/Decreto/D7626.htm. Acesso em 30 set.18.

Resolução CNE/CEB no. 2, de 19 de maio de 2010. Diretrizes Nacionais para a oferta de educação para jovens e adultos em situação de privação de liberdade nos estabelecimentos penais. Publicado no D.O.U. de 7/5/2010, Seção 1, P. 28.

7. CANÁRIO, Rui. A escola: o lugar onde os professores aprendem. In: Revista de Psicologia da Educação, PUC, São Paulo, n. 6, p. 9-29, 1998.

8. CONSELHO NACIONAL DE JUSTIÇA. Recomendação № 44 de 26/11/2013. Disponível em http://www.cnj.jus.br/busca-atos-adm?documento=1235. Acesso em 30 set. 18. 
DEPEN. Levantamento nacional de informações penitenciárias: INFOPEN - Junho de 2016. Brasília: Ministério da Justiça, 2017.

DI GIORGI, Cristiano Amaral G.; LEITE, Yoshie Ussami Ferrari. A qualidade da escola pública, na perspectiva democrática e popular. In: Série-Estudos - Periódico do Programa de Pós-Graduação em Educação da UCDB, n. 30 (jul/dez. 2010). Campo grande: UCDB, 1995.

11. ESTEVE, José M. Mudanças Sociais e função docente. In NÓVOA, Antonio (org). Profissão Professor. Portugal: Porto Editora, 1995, cap. IV p. 93-123. O mal-estar docente: a sala de aula e a saúde dos professores. Bauru: EDUSC, 1999.

13. FANFANI, E.T. Consideraciones sociologicas sobre profesionalización docente. Educação \& Sociedade, Campinas, v. 28, n.99, 335-353, maio/ago. 2007.

14. FREIRE, Paulo. Pedagogia da autonomia: saberes necessários à prática educativa. 8. ed. São Paulo: Paz e Terra, 1998. Política e educação: questões da nossa época. 5. ed. São Paulo: Cortez, 2001. (Coleção questões de nossa época, v. 23).

16. FOUCAULT, Michel. Vigiar e Punir. 38. ed. Petrópolis: Vozes, 2010.

GIROUX, Henry A. Os professores como intelectuais: rumo a uma pedagogia crítica da aprendizagem. Porto Alegre: Artes Médicas, 1997.

HADDAD, Sérgio. A ação de governos locais na educação de jovens e adultos. Revista Brasileira de Educação, v. 12, n. 35, maio/ago, 2007. Educação de jovens e adultos no Brasil (1986-1998). Série Estado do Conhecimento no 8. Brasília: MEC/Inep/Comped, 2002.

20. IMBERNÓN, Francisco. Qualidade do ensino e formação do professorado: uma mudança necessária. São Paulo: Cortez, 2016.

21. IRELAND, Timothy D. Educação de jovens e adultos como política pública no Brasil (2004-2010): os desafios da desigualdade e da diversidade. Rizoma freireano, n. 13, Instituto Paulo Freire de España, 2012. 
OLIVEIRA, Dalila Andrade. A reestruturação do trabalho docente: precarização e flexibilização. Educação \& Sociedade, Campinas, vol. 25, n. 89, p. 1127-1144, Set./Dez, 2004. Disponível em http://www.cedes.unicamp.br. Acesso em 14 Nov. 2016.

ONOFRE, Elenice Maria Cammarosano. Escola da prisão: espaço de construção da identidade do homem aprisionado? In: ONOFRE, Elenice Maria Cammarosano. A educação escolar entre as grades. São Carlos: EdUSCAR, 2007. Educação escolar na prisão: controvérsias e caminhos de enfrentamento e superação da cilada. In: LOURENÇO, Arlindo da Silva; ONOFRE, Elenice Maria Cammarosano. O espaço da prisão e suas práticas educativas: enfoques e perspectivas contemporâneas. São Carlos: EdUSCAR, 2011.

25. RIBEIRO, Vera Masagão; CATELLI JR., Roberto; HADDAD, Sérgio (Org.). A avaliação da EJA no Brasil: insumos, processos, resultados. Série documental, relatos de pesquisa 39. Brasília: Instituto nacional de Estudos e Pesquisas Educacionais Anísio Teixeira, 2015.

26. RIOS, Terezinha Azerêdo. Compreender e ensinar: por uma docência da melhor qualidade. São Paulo: Cortez, 2001.

27. SANTOS, Silvio dos. A educação escolar sob a ótica dos detentos. In: ONOFRE, Elenice Maria Cammarosano. A educação escolar entre as grades. São Carlos: EduFSCar, 2007.

28. SOUZA, Jesse. A ralé brasileira. 3. ed. ampl. São Paulo: Contracorrente, 2018.

29. TORRES, Eli Narciso. A produção social do discurso da educação para ressocialização de indivíduos aprisionados em Mato Grosso do Sul. Dissertação (Mestrado em Educação) Universidade Federal de Mato Grosso do Sul, 146 p. Campo Grande, 2011.

A gênese da remição de pena pelo estudo: o dispositivo jurídico-político e a garantia do direito à educação de privados de liberdade no Brasil. Tese de Doutorado (Doutorado em Educação) - Universidade Estadual de Campinas (Unicamp), Campinas/SP, 2017. Remição. Campo Grande: Próximo Take Filmes, (15 min), son., col, 2013. 


\section{Gesilane de Oliveira Maciel José}

Doutoranda em Educação pela UNESP/FCT. Mestrado em Educação pela UFMS/MS. Especialização em Direitos Humanos, Sistema Prisional e Execução Penal pela UNIFIL/PR. Especialização em Didática do Ensino Superior pela UNIFIL/PR. Especialização em Gestão Escolar pela UCB/RJ, Graduação em Comunicação Social - Relações Públicas pela UCDB/MS. Licenciatura em Pedagogia pelo CESUMAR/PR. Atualmente desenvolve pesquisas nas áreas de Formação e prática docente no sistema prisional e garantia do direito à educação.

\section{Eli Narciso da Silva Torres}

Socióloga e Doutora em Educação pelo Programa de Pós-Graduação em Educação da Universidade Estadual de Campinas - UNICAMP. Servidora do Departamento Penitenciário Nacional (DEPEN/MJSP) e Pesquisadora do FOCUS (Grupo de Pesquisa sobre Educação, Instituições e Desigualdade) na FE/UNICAMP. Atua como coordenadora do Observatório da Violência e Sistema Prisional que integra a Linha de Pesquisa: Sociedade, educação e sistema punitivo - CNPq.

\section{Como citar este documento:}

JOSÉ, Gesilane de Oliveira Maciel; TORRES, Eli Narciso da Silva. Docência no sistema penitenciário: o que as narrativas de professores revelam sobre a educação de adultos privados de liberdade. Reflexão e Ação, Santa Cruz do Sul, v. 27, n. 2, abr. 2019. ISSN 1982-9949. Disponível em: <https://online.unisc.br/seer/index.php/reflex/article/view/12626>. Acesso em: 2019. doi:https://doi.org/10.17058/rea.v27i2.12626. 